\title{
BMJ Open Perceptions of French general practitioners and patients regarding dextropropoxyphene withdrawal: a qualitative study
}

\author{
Aurélie Combier, ${ }^{1}$ Lucile Bon, ${ }^{1}$ Eric Van Ganse, ${ }^{2,3,4}$ Frédéric Aubrun, ${ }^{3,4,5}$ \\ Laurent Letrilliart ${ }^{1,4}$
}

To cite: Combier A, Bon L, Van Ganse E, et al. Perceptions of French general practitioners and patients regarding dextropropoxyphene withdrawal: a qualitative study. BMJ Open 2018;8:e21582. doi:10.1136/ bmjopen-2018-021582

- Prepublication history for this paper is available online. To view these files, please visit the journal online (http://dx.doi org/10.1136/bmjopen-2018021582).

$\mathrm{AC}$ and $\mathrm{LB}$ contributed equally.

Received 8 January 2018

Revised 4 July 2018

Accepted 27 July 2018

Check for updates

(c) Author(s) (or their employer(s)) 2018. Re-use permitted under CC BY-NC. No commercial re-use. See rights and permissions. Published by BMJ.

For numbered affiliations see end of article.

Correspondence to Professor Laurent Letrilliart; laurent.letrilliart@univ-lyon1.fr

\section{ABSTRACT}

Objectives Dextropropoxyphene (DXP), a step 2 analgesic commonly prescribed in France, was withdrawn from the French market in 2011 following a European decision due to its poor risk-benefit ratio. The purpose of this study was to explore the perceptions of French general practitioners (GPS) and patients regarding DXP withdrawal.

Design Qualitative study based on 26 individual semistructured interviews.

Setting Rhône-Alpes region of France.

Participants Thirteen patients and 13 GPs.

Methods Interviews were conducted to collect data concerning the status of DXP, its efficacy and safety, the conditions of DXP's withdrawal and its potential impact. The transcripts were analysed using NVivo software.

Results DXP was a very popular drug among both patients and GPs. Its withdrawal was a bad experience for patients and many GPs; these misunderstood the reasons for its withdrawal and several contested them. They generally recognised more benefits than risks of DXP and considered alternative drugs unsatisfactory. In the same period, a French court case regarding another drug led to distrust towards the pharmaceutical industry and healthcare institutions, which contributed to the negative feelings reported. However, the experience was positive for the GPs who had been alerted to the poor DXP risk-benefit ratio well before its withdrawal.

Conclusions Apart from physicians who were previously informed of its poor risk-benefit ratio, DXP withdrawal was not a good experience for patients and GPs. Better anticipation by the health authorities, in terms of pharmacoepidemiological surveillance and communication to healthcare professionals as well as the general public, should provide better acceptance of such a decision in the future.

\section{BACKGROUND}

In 2006, the combination of paracetamol and dextropropoxyphene (DXP, a step 2 analgesic) was the second-most prescribed analgesic in France (approximately 48 million boxes). ${ }^{1}$ However, the risk-benefit ratio of DXP had been controversial for many years. On the one hand, the efficacy of the
Strengths and limitations of this study

To our knowledge, this study is the first to have explored and compared the views of both patients and general practitioners (GPS) regarding dextropropoxyphene (DXP) withdrawal.

- The collected data were independently coded by two authors, the codes being secondarily discussed with another author, in order to provide internal triangulation.

- Although interviewed patients and GPs had diverse demographics and medical activities, the study design could have led to the recruitment of individuals particularly concerned by the DXP withdrawal and to an under-representation of the most neutral opinions of this event.

- Due to the time lag between the withdrawal and the interviews (3-5years), memory bias cannot be excluded.

DXP-paracetamol combination had not been widely assessed for chronic pain, and there was no strong evidence that it provided better analgesia than other step 1 or step 2 analgesics for postoperative pain, arthritis and musculoskeletal pain. ${ }^{23}$ On the other hand, in cases of overdose, DXP exposed patients to the risk of respiratory depression, cardiac conduction disorders and death. ${ }^{45}$ DXP toxicity is mainly due to its long half-life (15-37 hours), ${ }^{6}$ and it can be increased by concomitant use of alcohol or sedative drugs. ${ }^{7}$

As a result of many deaths due to voluntary or involuntary intoxications in Sweden (200 per year per 9 million inhabitants) and the UK (300-400 per year per 60 million inhabitants), the health authorities in these countries took restrictive measures and finally withdrew DXP from their markets in 2005 and 2007, respectively. Consequently, the European Medicines Agency reassessed the DXP risk-benefit ratio and in 2009 recommended its withdrawal from all European 
member states. ${ }^{8}$ In France, mortality from DXP intoxications was estimated to be around 65 deaths per year per 65 million inhabitants. ${ }^{9}$ The French Medicines Agency was initially reluctant to withdraw DXP from the national market considering that the risk to public health was lower than in the UK or Sweden, and fearing a higher toxicity in cases of substitution with tramadol. ${ }^{9}$ In 2010, a new study conducted in the USA found that DXP could cause fatal heart rhythm disorders even at the therapeutic doses allowed in this country. ${ }^{10}$ Based on these data, the French Medicines Agency finally decided to withdraw DXP in March 2011. ${ }^{11}$

The before/after evaluation performed in the UK found that the overall number of deaths from poisoning did not decrease and that the number of deaths involving codeine and tramadol increased. ${ }^{12}$ In France, the investigation of deaths due to analgesics was initiated in 2013, but it did not allow for the comparison of changes in the number of deaths attributable to the various analgesics due to a lack of consistent data prior to the withdrawal. ${ }^{13}$ Indeed, DXP and alternative analgesics were not specifically monitored before the European warning because no risk had been identified in France during DXP postmarketing surveillance. Apart from the surveillance process, there was probably insufficient communication of the reasons for the withdrawal, all the more important given that DXP was a popular drug among patients and GPs. In particular, it was very much focused on DXP risks and on recommendations for DXP substitution, ${ }^{14}$ without emphasising the lack of evidence for DXP efficacy.

Many patients in England and Wales have not found a satisfactory alternative to DXP after its withdrawal. ${ }^{15}$ The popularity of DXP and its controversial withdrawal in France suggest that this may have repercussions for pain management in primary care. A quantitative study did, however, find that there was no effect on pain intensity and daily activities in elderly patients in France, ${ }^{16}$ but the experience of this withdrawal by GPs and by other patients has not been studied in France, nor internationally. The purpose of this study was therefore to comparatively explore the perceptions of French GPs and patients regarding DXP withdrawal.

\section{METHODS}

We conducted a qualitative study based on individual semi-structured interviews and according to the grounded-theory approach. ${ }^{17}$ We were not aware of an established theory supporting the perceptions of the event under study. After a test phase, the interviews were held between April 2014 and March 2016.

\section{Sampling}

We used a purposive sampling procedure for GPs and patients, in order to include participants of various genders, ages and practice settings, and ultimately to collect a wide range of opinions. The GP sample consisted of private GPs from the Rhône-Alpes region of France who had been practising since at least January 2009. They were recruited via an email sent to the list of GPs of the Regional Union of Healthcare Professionals. The patient sample included adults who were regularly using DXP until its withdrawal. They were recruited in GP surgeries based on posters and flyers, and occasionally by using snowball sampling.

\section{Data collection}

Two semi-structured interview guides were developed based on a bibliographic review and discussion between the authors, one for GPs and the other for patients. Both included open-ended questions concerning the status of DXP, its effectiveness and safety, the conditions of DXP withdrawal and its potential impact. Patients and GPs chose the date and the place of the appointment, which could occur in a GP surgery, at the informant's home or in a public place. The interviews were conducted by LB for patients and by AC for GPs, who had been trained beforehand. They lasted a mean $36 \mathrm{~min}$ for patients and a mean 22 min for GPs.

\section{Data analysis}

Interviews were audio-recorded after obtaining oral consent from participants, and manually transcribed anonymously. They were then analysed using NVivo software. ${ }^{18}$ Our interpretive approach of GPs' and patients' perceptions (including experiences and views) was essentially inductive and the interview guides were modified according to the analysis of the first interviews. Data transcription, data entry and data coding were performed on a continuous basis during the data collection process, which allowed emerging themes to be further explored in later interviews. Thematic analysis was performed as the data were collected. Data were independently coded by two authors (AC, LB); the codes were later discussed with another author (LL) in order to provide internal triangulation. Regular meetings were held to reflect on the analytical process and to compare and discuss findings in order to reach consensus on recurrent themes. According to the grounded theory approach, data analysis was based on the constant comparison process and followed three distinct stages: open, axial and selective coding. The open coding of the transcripts identified the different concepts emerging from the data. Then, the codes were grouped into subcategories according to axial coding. Finally, selective codes emerged from the prioritisation of the axial codes into overarching categories, which included the status of the DXP, the characteristics of its withdrawal and the influence of past events.

\section{Patient and public involvement}

The development of the research question was informed by the clinical experience of two of the authors (LL and FA) in managing patients taking DXP. Some patients recruited other patients among their relations. 
Table 1 Characteristics of interviewed general practitioners (GPs) and patients

\begin{tabular}{|c|c|c|}
\hline Characteristics & GPs $(n=13)$ & $\begin{array}{l}\text { Patients } \\
(n=13)\end{array}$ \\
\hline \multicolumn{3}{|l|}{ Gender } \\
\hline Female & 5 & 8 \\
\hline Male & 8 & 5 \\
\hline \multicolumn{3}{|l|}{ Age (years) } \\
\hline $25-34$ & 2 & 2 \\
\hline $35-44$ & 1 & 0 \\
\hline $45-54$ & 3 & 3 \\
\hline $55-64$ & 7 & 5 \\
\hline $65-74$ & 0 & 3 \\
\hline \multicolumn{3}{|l|}{ Working/living area } \\
\hline Urban & 5 & 5 \\
\hline Semi-rural & 4 & 6 \\
\hline Rural & 4 & 2 \\
\hline \multicolumn{3}{|l|}{ GP trainer } \\
\hline Yes & 9 & \\
\hline No & 4 & \\
\hline \multicolumn{3}{|l|}{ Practice type } \\
\hline Solo & 1 & \\
\hline Group & 12 & \\
\hline \multicolumn{3}{|l|}{ Specialisation } \\
\hline Sports medicine/osteopathy & 3 & \\
\hline Homeopathy/mesotherapy & 1 & \\
\hline Medical expertise & 1 & \\
\hline Addictology & 1 & \\
\hline
\end{tabular}

\section{RESULTS}

Thirteen GPs and 13 patients were interviewed until data saturation was reached (ie, when no new significant concepts emerged) (table 1). The main themes identified from data analysis were: the DXP, its withdrawal (reasons, conditions, impact) and analgesic risk management.

\section{DXP: a popular drug}

Among step 2 analgesics, DXP was commonly used, sometimes without having previously tried a step 1 analgesic. DXP was mainly prescribed for recurrent musculoskeletal pain, such as low back pain, and for various pains including traumatic pain, menstrual pain, headache and toothache.

GP05: Propofan (DXP-paracetamol-caffeine), Diantalvic (DXP-paracetamol), we gave plenty of them, you know.

Patient (P) 12: I was taking it, I mean, like you could take a Doliprane (paracetamol).

The risk-benefit ratio for DXP seemed very positive for GPs and patients. First, both groups considered DXP to be equally or more effective than the other step 2 analgesics, and sometimes miraculous. Second, DXP was reported to be better tolerated than other step 2 analgesics, which were frequently associated with nausea and vertigo (eg, tramadol, codeine), or constipation and drowsiness (codeine). DXP was therefore popular among patients and GPs. Some patients were extraordinarily attached to it and sometimes used it off-label.

P08: It was even more like my, my blessed bread.

GP12: The dextropropoxyphene, from my past experience, had a tolerance that was close to perfect.

M04: For active patients having problems, it was something miraculous, which allowed us to often avoid sick leave.

P01: I was dependant, not to say, how to say, I could not go without it.

Patients also used various strategies to relieve their pain in addition to DXP: physiotherapy, joint injections, use of lumbar belt or orthopaedic soles, weight loss, psychotherapy or alternative medicines such as osteopathy, homeopathy and acupuncture.

P07: When I was in crisis, well, the first two days I only took the drugs because the physiotherapist couldn't touch me. Then, sometimes, the physiotherapist, he could start the therapy. Then, I reduced the Diantalvic (DXP-paracetamol).

\section{Misunderstanding and disagreement regarding DXP withdrawal}

Overall, both patients and GPs misunderstood the reasons for the withdrawal. They partly understood that it was due to potentially serious effects observed in other countries, especially in cases of misuse (ie, addiction, suicide attempts) and for different terms of use (packaging, dosage). Few were aware that DXP efficacy was not well-assessed.

GP02: I believe there were issues in some other countries with different doses, issues that I haven't checked in depth, it might have been a mistake by the way.

P08: I had heard on the television that they said it had been removed in England, because of too many suicides.

Other than those who had been informed of the risks associated with DXP a long time ago through reading a professional journal, many GPs considered the arguments for the DXP withdrawal excessive. For most patients, the withdrawal was not justified because they thought they were getting many benefits from the DXP and were not concerned by the risks. Several GPs and patients highlighted inconsistencies between the DXP withdrawal and the maintenance of other drugs on the market. 
GP06: But we already had the thought because we read (the journal) Prescrire, which warned a lot against this kind of product at that time.

GP08: I would have liked to know the rate, the number of people who have indeed had issues with that drug. Because if someone tells me, but that would make me fall off my chair, it's $15 \%$ to $20 \%$, I'd say it was worth it. If it is 1 in 100000 , then we have to remove all drugs.

P12: But I don't have the feeling that it had disastrous consequences on me, in fact it eased me, in my daily life.

P01: I did not understand why this drug was removed. And I have many echoes around me from people who have had the same reaction, who did not understand.

\section{An unanticipated withdrawal}

GPs and patients mainly heard about the DXP withdrawal through mainstream media. GPs were also informed by the French Medicines Agency, and the patients by their physicians. Many GPs and patients perceived the DXP withdrawal as a sudden decision, and some of them regretted that no restrictive measures had been previously taken. GPs made efforts to prepare and reassure their patients, but several of them faced difficulties in telling their patients that the drug they had been taking for years was being removed.

GP02: Well, it is often like that anyway. We are sometimes informed through the press rather than by the authorities.

P12: Well it has been a source of stress because I told myself: crap, what am I going to do?

GP08: But there were no preventive measures like: (...) the emergency services would be asked to give less of it (DXP-paracetamol), doctors would be asked to proceed with good judgement, to not give it out like it was Doliprane (paracetamol), and eventually to use secured prescriptions, why not? I don't know.

GPs had different feelings about the delay between the announcement of the decision and the withdrawal. Several were troubled that DXP prescription was still possible during this time, although the drug was presented as dangerous. Others appreciated still being allowed to prescribe it as they had difficulties in finding an alternative. Many patients regularly taking DXP had built up stockpiles of DXP and used all the tablets available, even after the withdrawal.

GP07: We get this kind of paradoxical message, a double constraint where on one hand, they suggest that we not prescribe it because it's toxic, and on the other hand, they allow us to prescribe it because it is not yet forbidden. This makes us think that if there was a problem it would be our responsibility.

GP10: I thought it was good, this progressive removal, as far as there were still possibilities to prescribe it to people who could not live without it. And it gave us more time to switch to a new drug.

P08: Even the day when I heard that they were going to cancel it and stuff, I had stocked up. I stocked as much as I could. And then I kept taking it at least 2 years, yes over 2 years.

The DXP withdrawal was an opportunity for GPs to reassess pain management and to diversify their prescriptions. DXP was mainly replaced by either a step 2 analgesic (ie, codeine, tramadol, opium) or by paracetamol, which was thereafter more often used by patients as a first-line treatment. In some cases, a non-steroidal anti-inflammatory drug or morphine was judged necessary. Some GPs easily replaced DXP with one of the many other treatment options, but other GPs were concerned about the possible side effects of the remaining opioid analgesics. Patients often felt that their substitute drug was not as satisfying as DXP.

GP07: So it helped to step down to regular paracetamol. It helps to do some sorting.

P05: I used to tell them, both the pharmacist and the doctor, I said it's not as good as Diantalvic (DXP-paracetamol)!

P11: I have tried other things, various dosages, et cetera, it has never been equivalent.

\section{DXP withdrawal: a rather bad experience}

The withdrawal disrupted the balance found by some patients with DXP, and sometimes affected their social life, their job or their mood. From then on, several patients felt more painful, while recognising that this may have been due merely to the progression of their condition. According to GPs, patients were still well-relieved, but their pain management was more complex, especially because of a poor tolerance for most alternative drugs. Several GPs mentioned their interest in the withdrawal in educating their patients on potential adverse drug events.

P01: It's like a brick, you remove one, then everything collapses.

P11: When I completely stopped, there was pain, in the muscles as well as in the joints, which was present but which was not the case before.

GP12: Less easy, less comfortable for pain treatment, that's it.

GP03: It was difficult because, well, we have been forced to switch to the other products available to us, but sometimes with big problems of tolerance.

Both GPs and patients perceived the DXP withdrawal as a very important and large-scale event. Apart from a few patients who used DXP only occasionally, most of them remembered the withdrawal as a bad experience and some expressed anger towards it. No patient reported improvement in his/her health status 
Table 2 Summary of the main perceptions of general practitioners (GPs) and patients regarding dextropropoxyphene (DXP) withdrawal

\begin{tabular}{ll}
\hline \multicolumn{1}{c}{ GPs } \\
\hline DXP medication & $\begin{array}{l}\text { Common prescription and use, high risk-benefit ratio, risk of dependence } \\
\text { Valued but non-exclusive strategy }\end{array}$ \\
\hline Reasons for withdrawal & $\begin{array}{l}\text { Misunderstanding, trend towards overestimation of benefits and underestimation of risks } \\
\text { Some GPs earlier informed through a professional journal }\end{array}$ \\
\hline Conditions of withdrawal & Information through mainstream media, lack of anticipation \\
\hline Withdrawal impact & Difficulties to inform patients \\
\hline Opportunity to reassess pain management, but concern about other analgesics \\
\hline Influence of past events & $\begin{array}{l}\text { Complex pain management, but opportunity to educate patients } \\
\text { Distrust of the pharmaceutical industry and healthcare institutions }\end{array}$ \\
\hline
\end{tabular}

The perceptions common to both GPs and patients are in bold characters.

following DXP discontinuation. Several of the GPs who had stopped prescribing DXP years earlier welcomed its withdrawal, as it justified their previous choice. Other GPs, as well as many patients, regretted it and wished DXP would be marketed again.

GP10: We used to talk about it during parties: CME (continuing medical education), peer groups; it was a pretty important event (laughs). So, we obviously couldn't ignore it.

P01: I have literally been..., it hurt me.

P08: If it still existed in countries, in other countries, I would go and get some.

GP04: I have much regretted it and I still regret it.

P10: In my mind, there's an important regret, then one can say that it is equivalent to an absence.

\section{The negative influence of past events}

GPs reported varying experiences with drug withdrawals: it did not matter to some of them, while others felt that their therapeutic options had decreased over the years without their approval.

GP05: If Ixprim (tramadol-paracetamol) didn't exist, we would do $[\ldots]$ a hot water bottle (laughs).

GP04: We get the feeling of having fewer and fewer things accessible to us to treat patients. Between the market withdrawals, the stock shortages, it's scary.

GPs and patients interpreted the DXP withdrawal as resulting from occult strategies of the pharmaceutical industry or even the health insurance system. Several court cases contemporaneous with the DXP withdrawal, and inconsistencies in the drug market regulations, reinforced their distrust.

GP04: So I think they are drugs that might have been less used, or might not have been expensive enough, not profitable enough for the pharmaceutical company and which led to its removal.

P13: You know, I see that when a drug is prescribed too much, it is removed.

P03: I think that because of Mediator (benfluorex), we are more suspicious.

GP05: I think that people, they get the feeling that the medical field has betrayed them when a drug gets removed, for sure! Something is given to them, and then they are told that they should no longer take it because it's toxic. It's as if someone tells you that you have been taking poison for 20 years!

GP07: We have seen it with the Mediator (benfluorex) which has been sadly notorious. We knew since 99 that it's shit, it is withdrawn in 2011 or around. I mean that it's a real problem, a real problem. And we have had that several times in a 25 year career.

To summarise, DXP was a popular drug among patients and GPs in France. Its withdrawal in 2011 was a bad experience for most patients and GPs. Both had misunderstood or did not agree with the reasons for this decision, and patients sometimes built up stocks of DXP. They saw more benefits than risks in using DXP, all the more when they were not aware of the lack of evidence for its efficacy nor for its risks beyond situations of misuse. In addition, both groups found the alternative drugs to DXP unsatisfactory, as patients and GPs reported poor tolerance of the other step two analgesics and patients felt more painful. Over the same period, a national court case, following complaints by patients treated earlier by benfluorex, led to a general distrust of the pharmaceutical industry and healthcare institutions. This distrust is likely to have blurred the understanding regarding the messages on DXP withdrawal and contributed to the negative feelings experienced. 


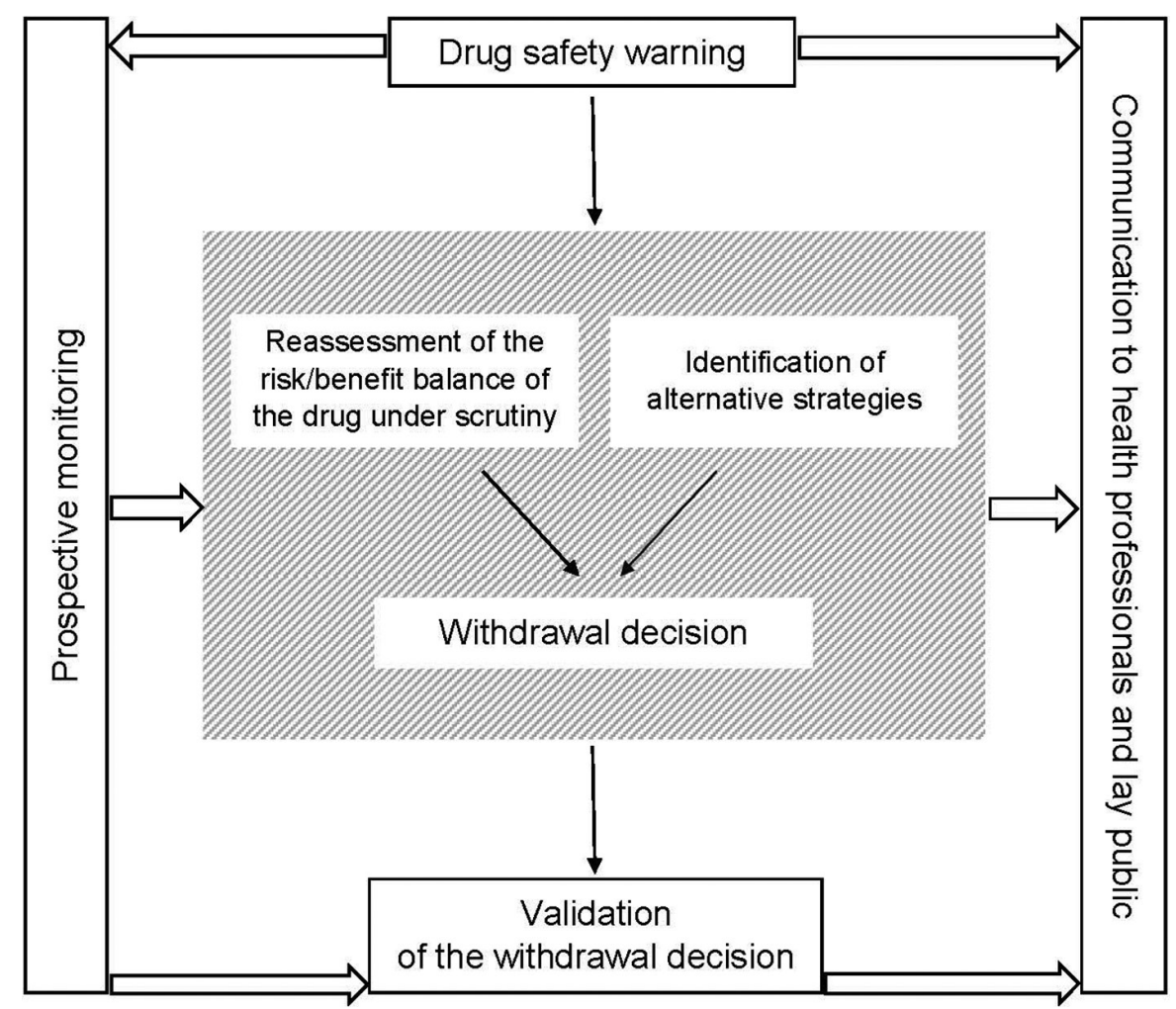

Figure 1 Proposed model for drug withdrawal decisions.

However, it was a positive experience for some GPs who had been alerted to the poor DXP risk-benefit ratio well before its withdrawal (table 2).

\section{DISCUSSION}

Healthcare professionals' and patients' perception of DXP withdrawal was primarily based on their experience of the benefits and risks of this drug as compared with other analgesics. Their perception was also influenced by their poor level of information and their distrust of the pharmaceutical industry and healthcare institutions. The importance of the clinical experience of the physician in the decision to prescribe DXP instead of paracetamol or aspirin has already been reported well before its withdrawal. ${ }^{19}$ Although as many as 462 identified medicinal products have been withdrawn from the market worldwide between 1953 and 2013, ${ }^{20}$ including 47 analgesic medications between 1965 and $2011,{ }^{21}$ we were not able to identify any previous qualitative or quantitative study on the perception of healthcare professionals or patients to these withdrawals in any country. A few studies have, however, examined the impact of drug safety warning on parental or provider perceptions. ${ }^{22}$ Limited quantitative data suggest that physicians disagreed with warnings from the Food and Drug Administration (FDA) on the use of droperidol ${ }^{23}$ or antiepileptic drugs ${ }^{24}$ as they felt that, according to their personal experience, there was no other drug with greater efficacy or improved safety profile. One study showed that parents disapproved of the FDA warning for over-the-counter cough and cold medications since they disagreed that they were dangerous and still believed they relieved symptoms. ${ }^{25}$ These studies did not explore the influence of the communication modalities nor the (dis)trust of the pharmaceutical industry and healthcare institutions on the perceptions of the healthcare professionals and the patients. Our findings therefore remain to be confirmed in future withdrawals of popular drugs.

GPs and patients did not understand the DXP withdrawal decision, as their perception of the risk-benefit ratio differed from the health authorities' evaluation. Benefits of painkillers are especially difficult to grasp by patients, and even by GPs, because of their poor pharmacological assessment and the importance of the placebo effect. There was indeed no strong evidence to support the important benefits experienced by patients using DXP. ${ }^{2}{ }^{3}$ As with many other old drugs, the efficacy of DXP had been poorly assessed, as well as for paracetamol. ${ }^{26}$ Patients treated with DXP may have felt a benefit due to the placebo effect, which is particularly frequent and intense with painkillers. It can relieve pain in $15 \%-52 \%$ of patients, ${ }^{27}$ and may even equal an injection of morphine in postoperative pain. ${ }^{28}$ Serious risks are also difficult to consider for GPs and even more so for patients, because they are rare, as illustrated by the number of deaths attributed to DXP in France, which has been estimated to be around 1.5 case per 1000 private GPs in 2009..$^{9}$ 
Many patients and GPs expressed distrust towards both healthcare institutions and the pharmaceutical industry. A survey about the French population's relationship with medicines found that only one in two people gives some credibility to information from the pharmaceutical industry and from the health authorities. ${ }^{29}$ Several patients and GPs have been struck by the French benfluorex case, which went public during the same period as the DXP withdrawal. ${ }^{30}$ Benfluorex was popular in France and largely prescribed off-label as an appetite suppressant for $>30$ years until it was discovered that it could cause valvular heart disease and pulmonary arterial hypertension. As a consequence, many patients treated with this drug have sued the pharmaceutical company marketing the drug and the French health authorities. ${ }^{31}$ This case, considered in France to be a national scandal, may have altered confidence in the drug management system and made the acceptance of DXP withdrawal difficult for patients and GPs.

Some GPs and most patients were unsatisfied with alternative drugs to DXP for three reasons. First, many patients felt their pain increased after DXP withdrawal. Such relapse was not observed in a French cohort study, but it was restricted to elderly people. ${ }^{15}$ Second, many patients also did not tolerate other step 2 analgesics. This observation is only partially consistent with French pharmacovigilance data, which found that the rate of adverse drug reactions reported for tramadol, but not for codeine, was higher than for DXP. ${ }^{32}$ Tolerance issues may help explain why patients largely turned to paracetamol, ${ }^{33}$ which could also contribute to relapsing pain. Finally, patients' dissatisfaction might also be due to DXP addiction. Indeed, behaviour close to addiction, such as stockpiling, fear of running out, off-label use or searching for backdoor procurement, were reported by interviewed patients. Such misuse could pertain to opioid addiction or even to pseudoaddiction, which is a controversial syndrome resulting from inadequate pain management. ${ }^{3435}$ This is of note as withdrawal from the market represented an imposed deprescription, which could sometimes result in withdrawal syndrome, as observed with opioids or benzodiazepines. ${ }^{36}$

\section{Strengths and weaknesses}

The principal strength of the study is that it explored and compared the views of both patients and GPs. Furthermore, the paper conforms to the standards for reporting qualitative research. ${ }^{37}$ A potential limitation is that preconceptions from the investigators may have influenced the findings. However, the two authors who performed interviews and primary analyses were medical interns (AC and LB), who had not been exposed to the DXP withdrawal. Conversely, the clinical experience of two authors (LL and FA) was useful to develop the interview guides. Another limitation is that, although interviewed patients and GPs had diverse demographics and medical activities, the study design could have fostered the recruitment of individuals particularly concerned by the DXP withdrawal and led to an under-representation of the most neutral opinions of this event. However, various opinions and experiences were collected from both groups until reaching saturation. Due to the 3-year to 5-year interval between the withdrawal and the interviews, memory bias cannot be excluded but this is likely to be limited as the studied event involved more the emotional than the factual memory of patients and GPs.

\section{Implications for future withdrawals}

In cases of future warnings on drug safety (within the framework of the risk management plan for new or recently marketed drugs), national and European health authorities should start collecting prospective data well before the withdrawal decision and continue the monitoring thereafter, including through qualitative studies. Such prospective monitoring is needed to assess the pharmacoepidemiological impact of drug withdrawal, including the use of alternative drugs and strategies, and ultimately to validate the withdrawal decision. Additionally, appropriately informing healthcare professionals and the general public at each stage of the withdrawal process (ie, warning, withdrawal decision and assessment) would ease acceptance of the decision and reinforce trust in the drug management system (figure 1). In addition, and before any safety warnings, an assessment of every blockbuster drug through randomised mega-trials should be considered if not available. ${ }^{38}$

\section{Author affiliations}

${ }^{1}$ Collège universitaire de médecine générale, Université de Lyon, Université Claude Bernard Lyon 1, Université Saint-Étienne, Lyon, France

${ }^{2}$ Faculté d'odontologie, Université Claude-Bernard-Lyon 1, UMR CNRS 5558, Lyon, France

${ }^{3}$ Groupe hospitalier Nord-hôpital de la Croix-Rousse, service de pneumologie, Hospices Civils de Lyon, CHU de Lyon, Lyon, France

${ }^{4}$ HESPER EA 7425, Université de Lyon, Université Claude Bernard Lyon 1, Université Saint-Étienne, Lyon, France

${ }^{5}$ Department of Anesthesiology and Critical Care, Hospices Civils de Lyon, Lyon, France

Acknowledgements The authors would like to thank all patients and GPs who have been interviewed in the study, the Regional Union of Healthcare Professionals for its logistical support and Professor Behrouz Kassai Koupai for the discussions regarding the results. The authors are also grateful to the College Lyonnais des Généralistes Enseignants (CLGE) and the Hospices Civils de Lyon for funding language editing.

Contributors LL, AC and LB conceived and designed the study, and they elaborated the interview guides. AC and LB conducted the interviews and the analysis, under the supervision of LL. EVG and FA provided clinical and pharmacoepidemiological context and contributed to the interpretation of the findings. $L L, A C$ and $L B$ drafted the manuscript. All authors reviewed and approved the final version of the article.

Funding The authors have not declared a specific grant for this research from any funding agency in the public, commercial or not-for-profit sectors.

Competing interests None declared.

Patient consent Not required.

Ethics approval The study was approved by the Ethics Committee of the University of Lyon 1 (Lyon, France) and the French national agency for national data protection (CNIL, $n^{\circ} 19162013$ ). Before each interview, the interviewer informed the participant on the subject of the interview and asked for his/her oral consent to recording and analysing the data to be collected. 
Provenance and peer review Not commissioned; externally peer reviewed.

Data sharing statement The data analysis tree is available on request from the corresponding author.

Open access This is an open access article distributed in accordance with the Creative Commons Attribution Non Commercial (CC BY-NC 4.0) license, which permits others to distribute, remix, adapt, build upon this work non-commercially, and license their derivative works on different terms, provided the original work is properly cited, appropriate credit is given, any changes made indicated, and the use is non-commercial. See: http://creativecommons.org/licenses/by-nc/4.0/.

\section{REFERENCES}

1. Prescrire rédaction. Dextropropoxyphène + paracétamol : toujours là. malgré les risques. Rev Prescrire 2007;27:735.

2. Li Wan Po A, Zhang WY. Systematic overview of co-proxamol to assess analgesic effects of addition of dextropropoxyphene to paracetamol. BMJ 1997;315:1565-71.

3. Collins SL, Edwards JE, Moore RA, et al. Single dose dextropropoxyphene, alone and with paracetamol (acetaminophen), for postoperative pain. Cochrane Database Syst Rev 2000:CD001440.

4. Young RJ, overdosage D. Pharmacological considerations and clinical management. Drugs 1983;26:70-9.

5. Afshari R, Maxwell S, Dawson A, et al. ECG abnormalities in coproxamol (paracetamol/dextropropoxyphene) poisoning. Clin Toxicol 2005;43:255-9.

6. Flanagan RJ, Johnston A, White AS, et al. Pharmacokinetics of dextropropoxyphene and nordextropropoxyphene in young and elderly volunteers after single and multiple dextropropoxyphene dosage. Br J Clin Pharmacol 1989;28:463-9.

7. Young RJ. Dextropropoxyphene overdosage. Pharmacological considerations and clinical management. Drugs 1983;26:70-9.

8. European Medicines Agency. Press release: European Medicines Agency recommends withdrawal of dextropropoxyphene-containing medicines. 2009 http://www.ema.europa.eu/docs/en_GB/document library/Press_release/2009/11/WC500010365.pdf (accessed 23 Oct 2017).

9. Agence Française de Sécurité Sanitaire des Produits de Santé. Médicaments contenant l'association dextropropoxyphène/ paracétamol : Recommandation de l'EMEA de retrait de ces médicaments à la suite de l'évaluation européenne et avis divergent de l'Afssaps. 2009 http://www.ansm.sante.fr/content/download/ 20487/248676/ (accessed 23 Oct 2017).

10. Food and Drugs Administration. Recommendation on a Regulatory Decision for Propoxyphene-containing Products. 2010 http://www.fda.gov/downloads/Drugs/DrugSafety/ PostmarketDrugSafetylnformationforPatientsandProviders/ UCM234349.pdf (accessed 23 Oct 2017).

11. Agence Française de Sécurité Sanitaire des Produits de Santé. Questions / Réponses. Retrait des médicaments contenant l'association dextropropoxyphène/paracétamol (Di-Antalvic $®$ et ses génériques) ou dextropropoxyphène/paracétamol/caféine (Propofan® et ses génériques). 2009 http://ansm.sante.fr/var/ansm site/storage/original/application/19ca2c73609691747d72c18b 65dfc21a.pdf (accessed 23 Oct 2017).

12. Handley SA, Flanagan RJ. Drugs and other chemicals involved in fatal poisoning in England and Wales during $2000-2011$. Clin Toxicol 2014;52:1-12.

13. Agence nationale de sécurité du médicament et des produits de santé. Compte rendu de séance. Comité technique des Centres d'Evaluation et d'Information sur la Pharmacodépendance CT022015023. Séance du 19 mars 2015. 2015 http://ansm.sante.fr/ var/ansm_site/storage/original/application/e9328677e7a48b722274 b90159035d1b.pdf (accessed 23 Oct 2017).

14. AFSSAPS. Mise au point. Prise en charge des douleurs de l'adulte modérées à intenses. Recommandations après le retrait des associations dextropropoxyphène/paracétamol et dextropropoxyphène/paracétamol/caféine. http://ansm.sante.fr/var/ ansm_site/storage/original/application/a6497f74fc2f18e8db002297 3f9327e1.pdf (accessed 23 Oct 2017).

15. Ottewell L, Walker DJ. Co-proxamol: where have all the patients gone? Rheumatology 2008;47:375.

16. Becquemont L, Delespierre T, Bauduceau B, et al. Consequences of dextropropoxyphene market withdrawal in elderly patients with chronic pain. Eur J Clin Pharmacol 2014;70:1237-42.

17. Strauss A, Corbin J. Basics of qualitative research: Techniques and procedures for developing grounded theory. Newbury Park: Sage publications, 2015

18. NVivo qualitative data analysis software, version 11. Doncaster: QSR International Pty Ltd, 2014.

19. Schwartz RK, Soumerai SB, Avorn J. Physician motivations for nonscientific drug prescribing. Soc Sci Med 1989;28:577-82.

20. Onakpoya IJ, Heneghan CJ, Aronson JK. Post-marketing withdrawal of 462 medicinal products because of adverse drug reactions: a systematic review of the world literature. BMC Med 2016;14:10.

21. Onakpoya IJ, Heneghan CJ, Aronson JK. Post-marketing withdrawal of analgesic medications because of adverse drug reactions: a systematic review. Expert Opin Drug Saf 2018;17:63-72.

22. Dusetzina SB, Higashi AS, Dorsey ER, et al. Impact of FDA drug risk communications on health care utilization and health behaviors: a systematic review. Med Care 2012;50:466-78.

23. Richards JR, Weiss SJ, Bretz SW, et al. The effects of the FDA warning on the use of droperidol by u.s. Emergency physicians. Cal J Emerg Med 2003;4:3-9.

24. Shneker BF, Cios JS, Elliott JO. Suicidality, depression screening, and antiepileptic drugs: reaction to the FDA alert. Neurology 2009;72:987-91.

25. Garbutt JM, Sterkel R, Banister C, et al. Physician and parent response to the FDA advisory about use of over-the-counter cough and cold medications. Acad Pediatr 2010;10:64-9.

26. Machado GC, Maher CG, Ferreira PH, et al. Efficacy and safety of paracetamol for spinal pain and osteoarthritis: systematic review and meta-analysis of randomised placebo controlled trials. BMJ 2015;350:h1225.

27. Beecher HK. The powerful placebo. J Am Med Assoc 1955;159:1602-6.

28. Levine JD, Gordon NC, Smith R, et al. Analgesic responses to morphine and placebo in individuals with postoperative pain. Pain 1981;10:379-89.

29. Ipsos. Observatoire sociétal du médicament $2015: 5$ ème vague d'étude menée par Ipsos pour le Leem sur le rapport des Français aux médicaments. https://www.leem.org/sites/default/files/ Observatoire-soci\%C3\%A9tal-du-M\%C3\%A9dicament2015.pdf (accessed 23 Oct 2017).

30. Mullard A. Mediator scandal rocks French medical community. Lancet 2011;377:890-2.

31. Menard J. Benfluorex: analysis of a drug-related public health crisis. Diabetes Metab 2011;37:169-75.

32. Tavassoli N, Lapeyre-Mestre M, Sommet A, et al. Reporting rate of adverse drug reactions to the French pharmacovigilance system with three step 2 analgesic drugs: dextropropoxyphene, tramadol and codeine (in combination with paracetamol). Br J Clin Pharmacol 2009;68:422-6.

33. Gaubert S, Vié M, Damase-Michel C, et al. Dextropropoxyphene withdrawal from a French university hospital: impact on analgesic drug consumption. Fundam Clin Pharmacol 2009;23:247-52.

34. Greene MS, Chambers RA. Pseudoaddiction: Fact or Fiction? An Investigation of the Medical Literature. Curr Addict Rep 2015;2:310-7.

35. Weissman DE, Haddox JD. Opioid pseudoaddiction-an iatrogenic syndrome. Pain 1989;36:363-6.

36. Le Couteur D, Banks E, Gnjidic D, McLachlan A, et al. Deprescribing. Aust Prescr 2011;34:182-5.

37. O'Brien BC, Harris IB, Beckman TJ, et al. Standards for reporting qualitative research: a synthesis of recommendations. Acad Med 2014;89:1245-51.

38. Loannidis JP. Mega-trials for blockbusters. JAMA 2013;309:239-40. 